\title{
LETTERS
}

\section{Tropical Stabilization of the Thermohaline Circulation in a Greenhouse Warming Simulation}

\author{
M. Latif, E. Roeckner, U. Mikolajewicz, And R. Voss \\ Max-Planck-Institut für Meteorologie, Hamburg, Germany
}

(Manuscript received 22 November 1999, in final form 23 December 1999)

\section{ABSTRACT}

\begin{abstract}
Most global climate models simulate a weakening of the North Atlantic thermohaline circulation (THC) in response to enhanced greenhouse warming. Both surface warming and freshening in high latitudes, the so-called sinking region, contribute to the weakening of the THC. Some models even simulate a complete breakdown of the THC at sufficiently strong forcing. Here results are presented from a state-of-the-art global climate model that does not simulate a weakening of the THC in response to greenhouse warming. Large-scale air-sea interactions in the Tropics, similar to those operating during present-day El Niños, lead to anomalously high salinities in the tropical Atlantic. These are advected into the sinking region, thereby increasing the surface density and compensating the effects of the local warming and freshening.
\end{abstract}

\section{Introduction}

The Atlantic thermohaline circulation (THC) is an important component of the global climate system (Broecker 1991). In the North Atlantic the Gulf Stream transports enormous amounts of heat poleward $(\sim 1 \mathrm{PW})$ as part of the THC, thereby warming western Europe. The THC is forced by convection at high latitudes, which causes dense surface waters to sink to deeper ocean layers, forming the so-called North Atlantic deep water (NADW). Strong and rapid changes in the intensity of the NADW formation have been reported from paleoclimatic records (Broecker et al. 1985), and it is well established that such changes exert a strong impact on the climate over large land areas (e.g., Manabe and Stouffer 1995, 1999; Schiller et al. 1997). Several papers have suggested that the THC may weaken in response to greenhouse warming (e.g., Mikolajewicz et al. 1990; Manabe et al. 1991; Stocker and Wright 1991; Cubasch et al. 1992; Manabe and Stouffer 1994; Rahmstorf 1995, 1997, 1999; Wood et al. 1999). Here, we

Corresponding author address: Dr. Mojib Latif, Max-Planck-Institut für Meteorologie, Bundesstrasse 55, D-20146 Hamburg, Germany.

E-mail: latif@drkz.de investigate the sensitivity of the THC to greenhouse warming using a global climate model that has been applied in various climate variability and response studies (Roeckner et al. 1996; Bacher et al. 1998; Oberhuber et al. 1998; Timmermann et al. 1999; Roeckner et al. 1999; Christoph et al. 1998; Ulbrich and Christoph 1999). It is shown that the tropical feedbacks associated with an increased El Niño frequency can stabilize the THC.

\section{Model}

The model is flux corrected (using annual mean corrections) with respect to heat and freshwater. The application of flux correction reflects serious errors in the individual model components. The effects of flux correction on the response characteristics of a model are largely unknown, but it has been shown that flux correction may cause misleading results (e.g., Neelin and Dijkstra 1995). It should be noted, however, that many studies addressing the stability of the THC have been conducted with flux-corrected models (e.g., Manabe and Stouffer 1994).

Our model employs a horizontal resolution over most of the globe of $2.8^{\circ} \times 2.8^{\circ}$. A special feature of the model is the higher meridional resolution of $0.5^{\circ}$ used in the tropical oceans, which enables a realistic simu- 


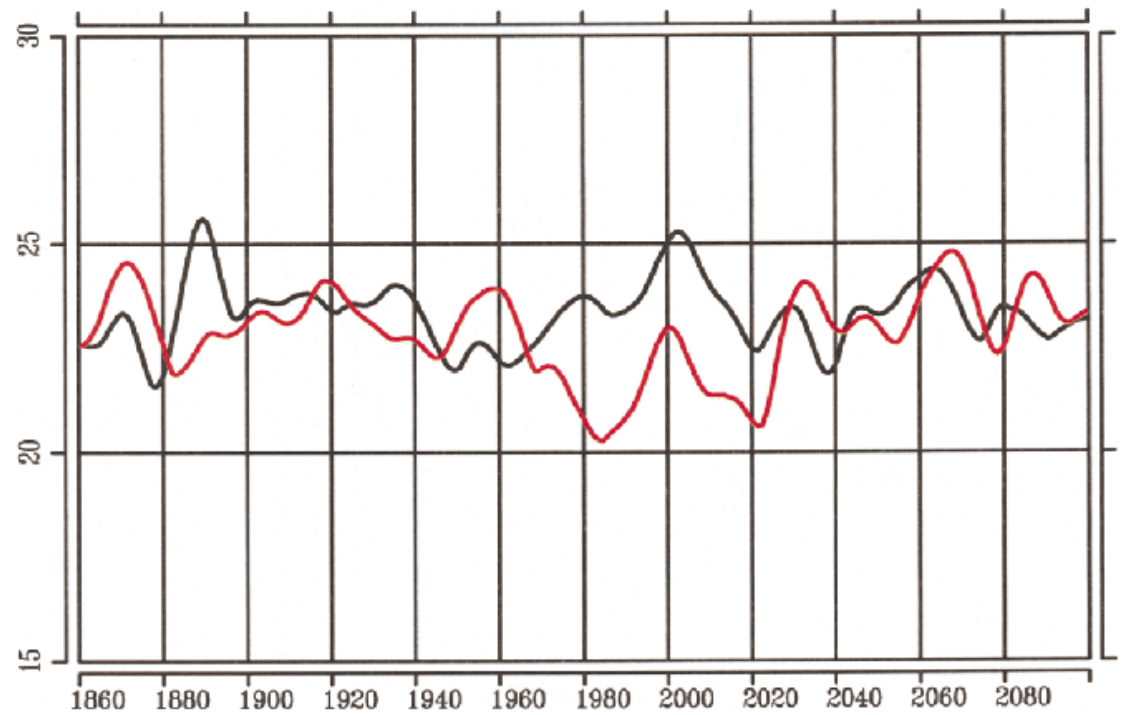

FIG. 1. Time series of the maximum overturning (Sv) in the North Atlantic for the control integration with present-day greenhouse gas concentrations (black line) and the transient greenhouse warming simulation (red line).

lation of the El Niño-Southern Oscillation phenomenon (Roeckner et al. 1996; Bacher et al. 1998; Oberhuber et al. 1998), the strongest natural interannual climate fluctuation. We performed two integrations. The first experiment is a 240 -yr-long control integration with fixed present-day concentrations of greenhouse gases. In the second experiment the model was forced by in- creased greenhouse gas concentrations, giving approximately the historical increase in radiative forcing from 1860 to 1990 (Roeckner et al. 1999) and subsequently (up to 2100) by increases according to the Intergovernmental Panel on Climate Change (IPCC) scenario IS92a (IPCC 1992). The effects of anthropogenic sulfate emissions are not included in the simulation.
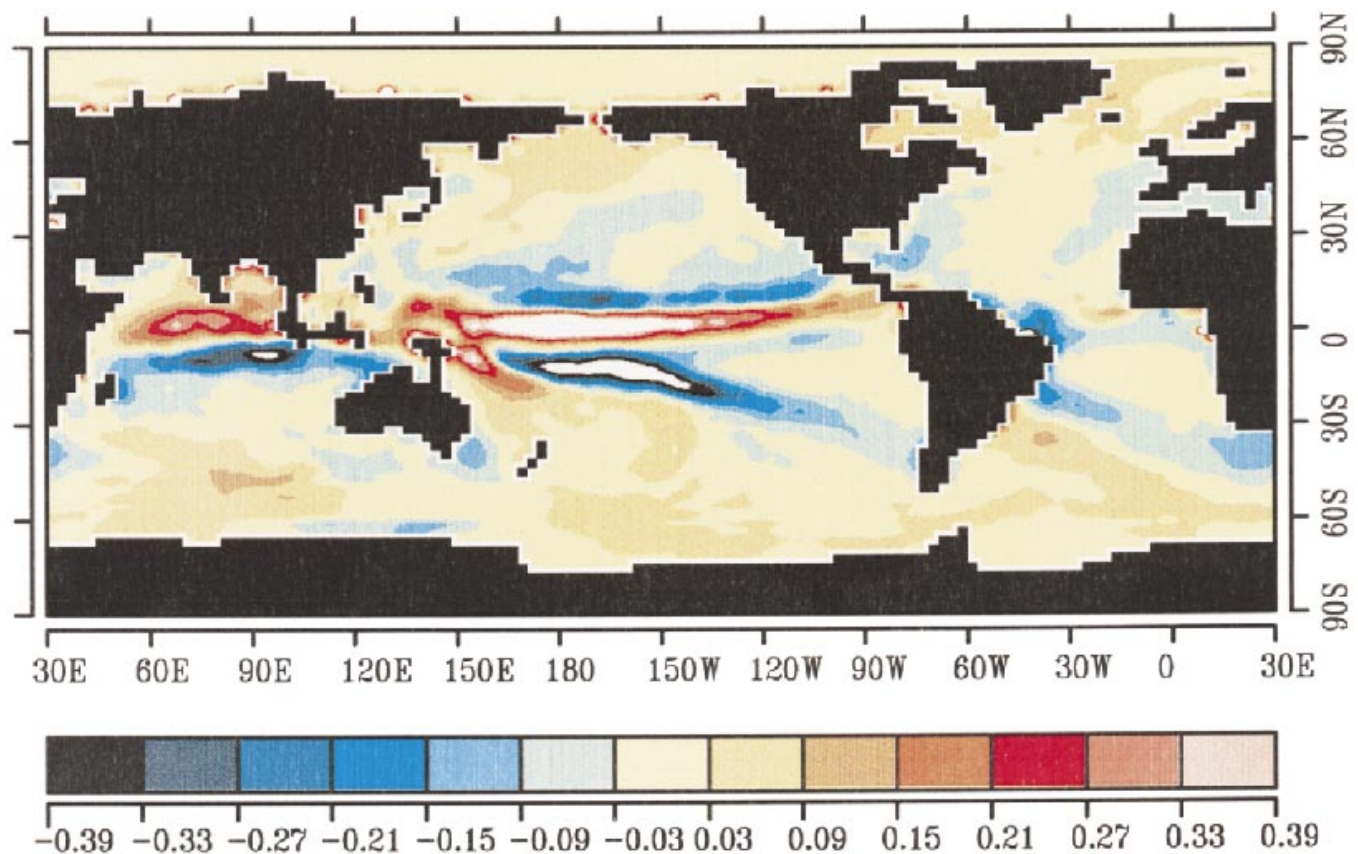

FIG. 2. Centennial linear trend in the freshwater flux $(P-E+R$, precipitation minus evaporation plus river runoff) $\left.[\mathrm{mm} \text { (day decade })^{-1}\right]$ obtained from the transient greenhouse warming simulation and computed over the period 2000-2100. Note the freshening in the equatorial Pacific associated with the increased El Niño frequency and the strongly reduced freshwater influx over the tropical Atlantic. 

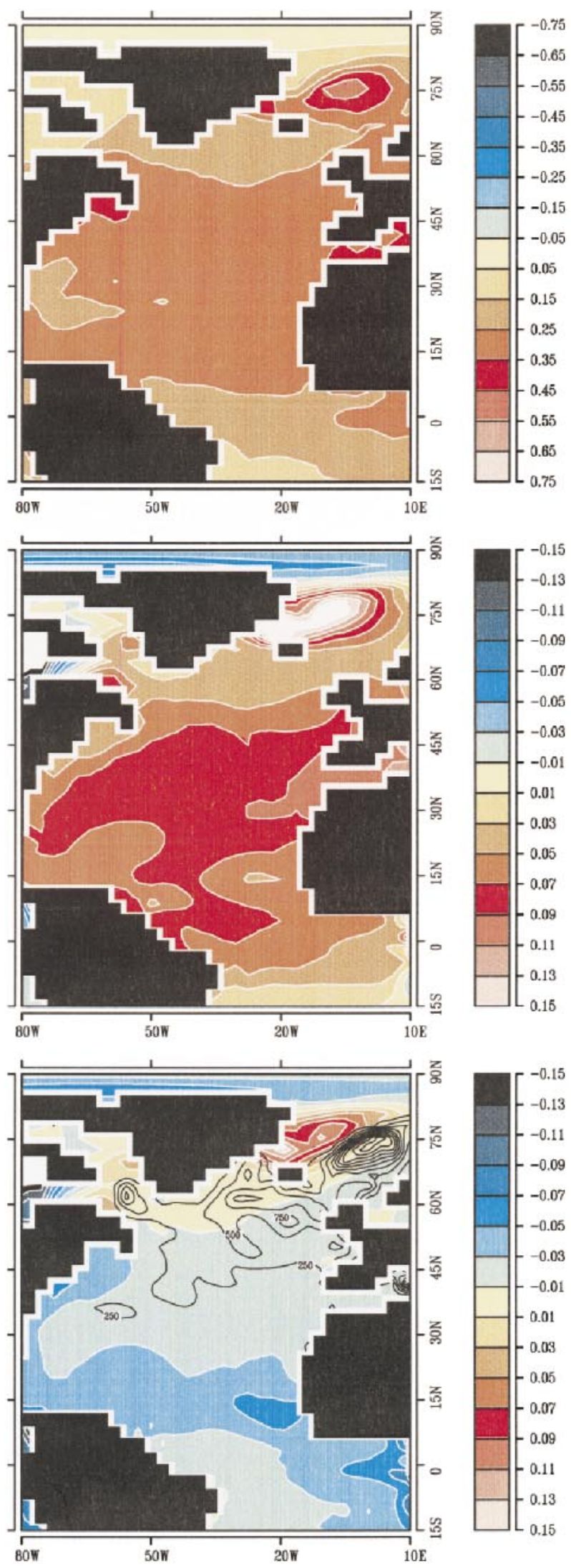

\section{Results}

The control run simulates the THC in the North Atlantic reasonably well (Zhang et al. 1998), with a maximum overturning of about 23 Sverdrups (Sv) at a depth of about $2000 \mathrm{~m}$ and an NADW outflow at $30^{\circ} \mathrm{S}$ of about $15 \mathrm{~Sv}\left(1 \mathrm{~Sv}=10^{6} \mathrm{~m}^{3} \mathrm{~s}^{-1}\right)$ at a depth of about $1500 \mathrm{~m}$. However, the model fails to simulate the inflow of the very dense Antarctic bottom water into the North Atlantic. The THC is relatively stable during the control integration but exhibits some superimposed interdecadal variability (Fig. 1). The range of this internal THC variability is consistent with that simulated by other global climate models (Delworth et al. 1993; Timmermann et al. 1998). In the transient greenhouse warming simulation the THC remains also stable, with a slight decrease during the first half and a slight increase during the second half. Thus, our model predicts a stable THC rather than a weakening THC as simulated by most other global models (Rahmstorf 1999).

The physics responsible for the stabilization of the THC in our model is related to tropical air-sea interactions. The regional distribution of the simulated sea surface temperature (SST) trend is characterized by warming in most ocean areas, with some cooling tendency in certain regions around Antarctica (not shown; see also Roeckner et al. 1999). Of particular importance is the El Niño-like warming trend in the eastern equatorial Pacific. As has been described in Timmermann et al. (1999), this warming results from air-sea interactions similar to those producing present-day El Niños and has strong impacts on the entire tropical climate system. The model simulates strongly enhanced precipitation over the central equatorial Pacific (Fig. 2), a feature observed during present-day El Niños (Philander 1990; Ropelewski and Halpert 1987). This leads to adiabatic warming and drying through anomalous subsidence over northeast Brazil and the tropical Atlantic, thereby reducing precipitation and river runoff from the Amazon catchment area and increasing evaporation from the tropical Atlantic. The model simulates an additional fresh water export from the Atlantic to the Pacific of about $0.015 \mathrm{~Sv}$ decade ${ }^{-1}$, in comparison to only 0.005 $\mathrm{Sv}$ decade $^{-1}$ in another Max Planck Institute coupled model simulating a weakening of the THC (Mikolajewicz and Voss 2000) as discussed by Rahmstorf 1999 (his Fig. 2). Such an enhanced freshwater export is also ob-

$\leftarrow$

FIG. 3. Centennial linear trends of selected quantities in the North Atlantic obtained from the transient greenhouse warming simulation and computed over the period 2000-2100. (a) Trend in SST $\left({ }^{\circ} \mathrm{C}\right.$ decade ${ }^{-1}$ ), (b) trend in sea surface salinity (psu decade $\left.{ }^{-1}\right)$, (c) trend in surface density $\left[\mathrm{kg}\left(\mathrm{m}^{3} \text { decade }\right)^{-1}\right]$. The depth of the convection (m) simulated for the month of Feb in the control integration is shown as contours (contour interval is $250 \mathrm{~m}$ ). The two main convection regions in the Labrador and Greenland-Iceland-Norwegian Seas are simulated realistically by the model. No significant change in the density is simulated in these regions. 

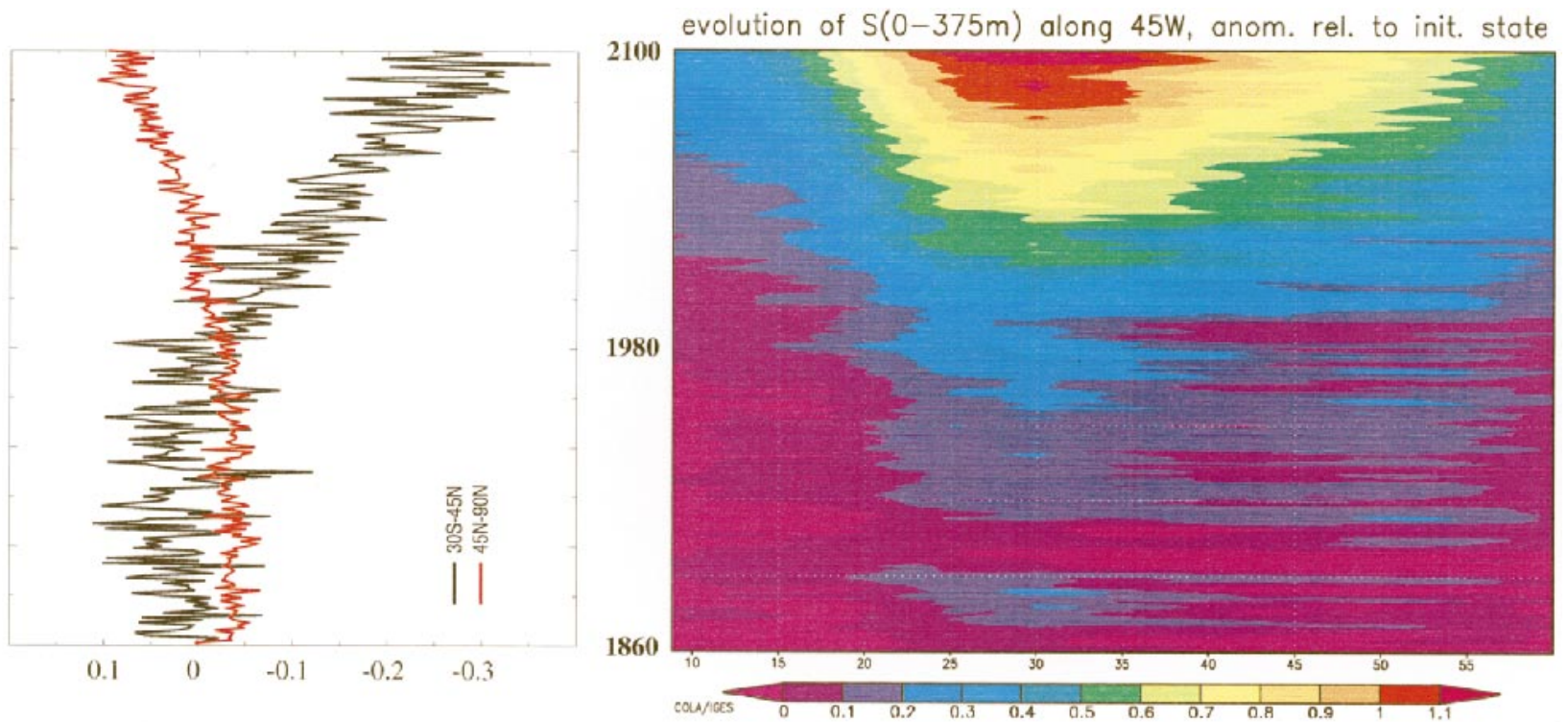

FIG. 4. (a) Anomalous freshwater input (Sv) into the Atlantic in the region $30^{\circ} \mathrm{S}-45^{\circ} \mathrm{N}$ (black curve) and into the mid- and high latitudes $\left(45^{\circ}-90^{\circ} \mathrm{N}\right.$, red curve). (b) Temporal evolution of the salinity anomalies (psu) averaged over the upper $375 \mathrm{~m}$ as function of latitude along $45^{\circ} \mathrm{W}$. The northward propagation of the salinity anomalies from the subtropics to higher latitudes can be clearly seen by the tilt of the contours. All anomalies are calculated by subtracting the initial values.

served during present-day El Niños (Schmittner et al. 2000).

The reduced freshwater flux induces anomalously high salinities in the tropical Atlantic Ocean (Fig. 3b). We averaged the freshwater fluxes over two regions $\left(30^{\circ} \mathrm{S}-45^{\circ} \mathrm{N}\right.$ and $\left.45^{\circ}-90^{\circ} \mathrm{N}\right)$ and display their time evolutions in Fig. 4a. The freshwater input to the Atlantic toward the end of the integration is strongly reduced by about $0.3 \mathrm{~Sv}$ in the tropical region, while it is enhanced by about $0.1 \mathrm{~Sv}$ in the mid- and high latitudes. Thus, the changes in the freshwater flux will tend to enhance the salinity in the Tropics and to reduce the salinity in the mid- and higher latitudes, with changes in the Tropics being considerably stronger. We time-integrated the anomalous freshwater flux forcing into the Atlantic and Arctic poleward of $30^{\circ} \mathrm{S}$. This quantity has been compared to the anomalous salt content of the upper $375 \mathrm{~m}$ at the end of the integration. The actual salt gain of the upper Atlantic amounts to about two-thirds of the total implied freshwater-induced salt gain. We do not expect a perfect match, since the integration domain is not closed. However, this computation shows that the salinity anomalies can easily be explained by the changes in atmospheric moisture transport.

The poleward transport of the salt anomaly and the mixing within the subtropical gyre result in increased surface salinity over the entire North Atlantic Ocean. The poleward propagation of the anomalously high salinities is visualized by a Hovmoeller diagram showing the temporal evolution of the salinity anomalies averaged over the upper $375 \mathrm{~m}$ in a meridional section along $45^{\circ} \mathrm{W}$ (Fig. 4b). The salinity transport overrides the counteracting local freshwater influx through enhanced precipitation (Figs. 2, 4a) and warming in the high latitudes of the North Atlantic (Fig. 3a), which are the principal feedbacks in models predicting a reduced THC.

We computed separately the salt and temperature contributions in the change of the surface density, which is the crucial quantity for deep water formation. The linear expansion coefficients for temperature and salinity for a temperature of $5^{\circ} \mathrm{C}$ and salinity of $35 \mathrm{psu}$, which are characteristic values for the sinking region, amount to $-0.12 \mathrm{~kg} \mathrm{~m}^{-3} \mathrm{~K}^{-1}$ and $0.79 \mathrm{~kg} \mathrm{~m}^{-3} \mathrm{psu}^{-1}$, respectively. Given an SST change of about $0.3^{\circ} \mathrm{C}$ decade $^{-1}$ and a salinity change of about 0.05 psu decade ${ }^{-1}$ (Figs. $3 a, b)$, this yields comparable density changes of about $0.4 \mathrm{~kg}\left(\mathrm{~m}^{3} \text { decade }\right)^{-1}$. A calculation using the complete equation of state yields a similar result, with almost no density change in the regions of strongest deep water formation (Fig. 3c). Thus, in our transient greenhouse warming simulation the poleward salt transport is an important feedback process, in addition to the freshening through increased precipitation and warming in the high latitudes, and the net outcome is a stable rather than a weakening THC.

Are the changes in the hydrological cycle large enough to have a significant effect on the THC? Typical threshold values for a complete collapse of the presentday THC are in the range of $0.1-0.4 \mathrm{~Sv}$ for anomalous freshwater input into the North Atlantic (e.g., Stocker and Wright 1991; Rahmstorf 1995; Schiller et al. 1997). Given a change of the order of $-0.2 \mathrm{~Sv}$ in our simulation, it is not surprising that this effect is large enough to balance the thermally induced weakening of the THC. 


\section{Concluding remarks}

The tropical air-sea interactions that stabilize the thermohaline circulation in our model simulation are not adequately represented in most global climate models applied hitherto to the problem of anthropogenic climate change, mainly because of their too-coarse resolution in the Tropics. This feedback needs to be studied more carefully in relation to the destabilizing feedbacks considered in previous investigations. At this stage of analysis we can conclude only that the response of the THC to enhanced greenhouse warming is still an open question. The uncertainty arises from model shortcomings in the representation of key physical processes, such as the hydrological cycle. Our results may be important also in view of paleoclimatic variations, because they indicate that variations in the Tropics may synchronize changes globally.

Acknowledgments. We would like to thank K. Hasselmann for his comments on an earlier version of the manuscript. This work was supported by the European Union's SINTEX programme and the German government's Ocean CLIVAR programme. The model integrations were performed at the Deutsches Klimarechenzentrum.

\section{REFERENCES}

Bacher, A., J. M. Oberhuber, and E. Roeckner, 1998: ENSO dynamics and seasonal cycle in the tropical Pacific as simulated by the ECHAM4/OPYC3 coupled general circulation model. Climate Dyn., 14, 431-450.

Broecker, W. S., 1991: The great ocean conveyor. Oceanography, 4, 79-89.

—, D. M. Peteet, and D. Rind, 1985: Does the ocean-atmosphere system have more than one stable mode of operation? Nature, 315, 21-26.

Christoph, M., T. P. Barnett, and E. Roeckner, 1998: The Antarctic circumpolar wave in a coupled ocean-atmosphere GCM. J. Climate, 11, 1659-1672.

Cubasch, U., K. Kasselmann, H. Höck, E. Maier-Reimer, U. Mikolajewicz, B. D. Santer, and R. Sausen, 1992: Time-dependent greenhouse warming computations with a coupled ocean-atmosphere model. Climate Dyn., 8, 55-69.

Delworth, T., S. Manabe, and R. J. Stouffer, 1993: Interdecadal variations of the thermohaline circulation in a coupled ocean-atmosphere model. J. Climate, 6, 1993-2011.

IPCC, 1992: Climate Change 1992. The Supplementary Report to the IPCC Scientific Assessment. J. T. Houghton, B. A. Callander, and S. K. Varney, Eds., Cambridge University Press, 200 pp.

Manabe, S., and R. J. Stouffer, 1994: Multiple-century response of a coupled ocean-atmosphere model to an increase of atmospheric carbon dioxide. J. Climate, 7, 5-23.

- , and -1995 : Simulation of abrupt climate change induced by freshwater input to the North Atlantic Ocean. Nature, 378, $165-167$.

, 1999: The role of thermohaline circulation in climate. Tellus, 51, 91-109.

, - - M. Spelman, and K. Bryan, 1991: Transient responses of a coupled ocean-atmosphere model to gradual changes of atmospheric $\mathrm{CO}_{2}$. Part I: Annual mean response. J. Climate, 4, 785-818.

Mikolajewicz, U., and R. Voss, 2000: The role of the individual airsea flux components in $\mathrm{CO}_{2}$-induced changes of the ocean's circulation and climate. Climate Dyn., in press.

- B. D. Santer, and E. Maier-Reimer, 1990: Ocean response to greenhouse warming. Nature, 345, 589-593.

Neelin, J. D., and H. A. Dijkstra, 1995: Ocean-atmosphere interaction and tropical climatology. Part I: The dangers of flux correction. J. Climate, 8, 1325-1342.

Oberhuber, J. M., E. Roeckner, M. Christoph, M. Esch, and M. Latif, 1998: Predicting the '97 El Niño event with a global climate model. Geophys. Res. Lett., 25, 2273-2276.

Philander, S. G. H., 1990: El Niño, La Niña and the Southern Oscillation. Academic Press, $293 \mathrm{pp}$.

Rahmstorf, S., 1995: Bifurcations of the Atlantic thermohaline circulation in response to changes in the hydrological cycle. Nature, 378, 145-149.

, 1997: Risk of sea-change in the Atlantic. Nature, 388, 825826.

-, 1999: Shifting seas in the greenhouse? Nature, 399, 523-524.

Roeckner, E., J. M. Oberhuber, A. Bacher, M. Christoph, and I. Kirchner, 1996: ENSO variability and atmospheric response in a global atmosphere-ocean GCM. Climate Dyn., 12, 737-754.

- L. Bengtsson, J. Feichter, J. Lelieveld, and H. Rodhe, 1999: Transient climate change simulations with a coupled atmosphere-ocean GCM including the tropospheric sulfur cycle. $J$. Climate, 12, 3004-3032.

Ropelewski, C. F., and M. Halpert, 1987: Global and regional scale precipitation patterns associated with the El Niño/Southern Oscillation. Mon. Wea. Rev., 115, 1606-1627.

Schiller, A., U. Mikolajewicz, and R. Voss, 1997: The stability of the thermohaline circulation in a coupled ocean-atmosphere model. Climate Dyn., 13, 325-348.

Schmittner, A., C. Appenzeller, and T. F. Stocker, 2000: Enhanced Atlantic freshwater export during El Niño. Geophys. Res. Lett., in press.

Stocker, T. F., and D. G. Wright, 1991: Rapid transitions of the ocean's deep circulation induced by changes in surface water fluxes. Nature, 351, 729-732.

Timmermann, A., M. Latif, R. Voss, and A. Groetzner, 1998: Northern Hemisphere interdecadal variability: A coupled air-sea mode. $J$. Climate, 11, 1906-1931.

- J. Oberhuber, A. Bacher, M. Esch, M. Latif, and E. Roeckner, 1999: Increased El Niño frequency in a climate model forced by future greenhouse warming. Nature, 398, 694-697.

Ulbrich, U., and M. Christoph, 1999: A shift of the NAO and increasing storm track activity over Europe due to anthropogenic greenhouse gas forcing. Climate Dyn., 15, 551-559.

Wood, R. A., A. B. Keen, J. F. Mitchell, and J. M. Gregory, 1999: Changing spatial structure of the thermohaline circulation in response to atmospheric $\mathrm{CO}_{2}$ forcing in a climate model. Nature, 399, 572-575.

Zhang, X.-H., J. Oberhuber, A. Bacher, and E. Roeckner, 1998: Interpretation of interbasin exchange in an isopycnal ocean model. Climate Dyn., 14, 725-740. 